\title{
A Preliminary Analysis of Immigrant Cattle Feedyard Worker Perspectives on Job-Related Safety Training
}

\author{
Athena K. Ramos ${ }^{1, *}\left(\mathbb{D}\right.$, Gustavo Carlo ${ }^{2}$, Kathleen M. Grant ${ }^{3}$, Casper Bendixsen ${ }^{4}$ (D), \\ Axel Fuentes ${ }^{5}$ and Rodrigo Gamboa ${ }^{6}$ \\ 1 Center for Reducing Health Disparities, Department of Health Promotion, University of Nebraska Medical \\ Center, Omaha, NE 68198-4340, USA \\ 2 Department of Human Development and Family Science, University of Missouri, \\ Columbia, MO 65211, USA; carlog@missouri.edu \\ 3 College of Medicine, University of Nebraska Medical Center/VA Nebraska-Western Iowa Health Care \\ Center, Omaha, NE 68105, USA; Kathleen.Grant2@va.gov \\ 4 National Farm Medicine Center, Marshfield Clinic Research Institute, Marshfield, WI 54449, USA; \\ bendixsen.casper@mcrf.mfldclin.edu \\ 5 Rural Community Workers Alliance, Milan, MO 63556, USA; axelrcwa@gmail.com \\ 6 Independent Consultant, Grand Island, NE 68803, USA; rogadous@yahoo.com \\ * Correspondence: aramos@unmc.edu; Tel.: +1-402-559-2095
}

Received: 30 July 2018; Accepted: 29 August 2018; Published: 2 September 2018

\begin{abstract}
Immigrants comprise a large percentage of the agricultural labor force in the United States. They are a vulnerable worker population and often have fewer occupational and social protections. Latino immigrant cattle feedyard workers $(N=68 ; 59$ men; mean age $=38.7$ years $)$ in the central Midwest reported on their perceptions and preferences for job-related safety training and practices. Preliminary findings indicate that approximately $40 \%$ of workers reported that they had not received any health or safety training from their current employer, and only about $13 \%$ had ever participated in any Occupational Safety and Health Administration (OSHA) safety training program. In-person training, videos, or shadowing another worker were the most frequent methods of safety training reported by those who had received training. More than $90 \%$ were interested in receiving more information about health and safety related to their job. Workers preferred that safety information be provided through in-person training at the job site, videos (particularly those accessible through media sources such as YouTube), and written materials. Specific topics that workers were interested in obtaining more information about included zoonoses, low-stress cattle handling, injury prevention, hazard and injury reporting, chemical and equipment safety, and teamwork. Furthermore, a majority of participants preferred to receive information in Spanish. Results may help guide the development of future materials and training strategies to better suit the needs of the growing immigrant workforce in production agriculture.
\end{abstract}

Keywords: farmworkers; Latino/Hispanic; agricultural health and safety; feedlots

\section{Introduction}

Immigrant labor is vital to production agriculture in the United States. Traditionally, these workers were engaged in seasonal agricultural labor; however, more immigrants are settling into communities. Many are now engaged in year-round employment in livestock production, such as on cattle feedyards and dairies. In fact, it is estimated that approximately half of the feedyard labor force in the United States is comprised of immigrant workers [1]. Unfortunately, only limited data about these workers are available; however, it is clear that livestock production jobs are among the most hazardous in 
agriculture [2,3]. For example, hired workers in the beef cattle ranching and farming (North American Industry Classification System (NAICS) code, 11211) had a "days away from work" rate of 260/10,000, while the rate for all industries combined was 100/10,000 [4]. In 2015 alone, there were 69 fatalities in beef cattle ranching and feedyards [5], and 10 of these occurred in Nebraska and Kansas [6,7].

On average, cattle feedyards employ one person per 1095 head of cattle [8]. Feedyards are often organized into different departments with a variety of jobs, such as pen rider/cowboy, hospital/sick pen, cattle processing, feed mill, feed delivery, yard and equipment maintenance, administration, and security. Pen riders/cowboys ride through the cattle either on horseback or on an all-terrain vehicle (ATV), every day, to monitor the animals' health status. Individuals who work the hospital/sick pen administer treatments to sick cattle. Processing cattle refers to handling animals as they enter and exit the feedyard. Tasks may include weighing the cattle, checking them for pregnancy, administering vaccines, castrating, and removing horns. At the feed mill, grains are processed and mixed to meet the dietary needs of the cattle, and workers use various types of machinery and equipment to manufacture and store the feed. Feed is delivered to the feed bunks by feed delivery truck drivers. Yard and equipment maintenance includes maintaining and repairing all facilities on the yard, such as fences, gates, chutes, feed bunks, buildings, and lagoons. Administrative personnel manage cattle records and feedyard operations. Finally, individuals working security ensure that cattle are safe, and that no unauthorized people are on the property that could compromise the health and wellbeing of the cattle or the business [9]. Workers may specialize in specific tasks based on the size of the feedyard operation; however, on smaller operations, workers may do any of the necessary tasks, even those that they have not been trained to do, which may put them at additional risk. Cattle feedyard workers are exposed to a variety of occupational hazards, such as those related to animal handling, including both cattle and horses (e.g., broken bones or lacerations); equipment and machinery (e.g., slips, trips, and falls; being crushed; or 'caught in-between'); vehicles (e.g., 'struck by' injuries); chemicals, medications, and sharps (e.g., needlesticks or poisoning); facilities including gates, chutes, or lagoons (e.g., electrocution, inhalation, or drowning); and extreme weather.

Due to the risks associated with these hazards, safety training is vital. The Occupational Safety and Health Administration (OSHA) provides guidance on the type of training that should be provided to workers, and although there are few agriculture specific OSHA regulations, the General Duty Clause applies. Therefore, training related to personal protective equipment, machine guarding, lock-out/tag-out, confined space, vehicle safety, and fall protection is still relevant. Ensuring that someone on the feedyard is trained in cardiopulmonary resuscitation (CPR) and first aid is also required, since most feedyards are not in close proximity to an emergency facility. Finally, if the feedyard has more than 10 employees then they are bound by the OSHA recordkeeping rules and are required to maintain OSHA 300 logs documenting any serious occupational injuries or illnesses; consequently, workers, particularly those in supervisory roles, should be trained on how to complete and maintain these records $[10,11]$.

All workers have the right to appropriate job-related training and safety information [12], but immigrant workers are less likely to receive such training and information, particularly if they have limited English proficiency [13]. Training should occur at the time of hire, but also at regular intervals during employment [14]. Training should be provided in the worker's primary language and incorporate both social and cultural differences commonly found among the worker population [15]. Training may improve safety knowledge, attitudes, and beliefs, and lead to positive changes in safety behaviors and health outcomes. In one study of Colorado dairies, workers who had received task-related training were four times less likely to report an injury on the job, and the authors concluded that incorporating health and safety information into task-related training could be both feasible and effective [14]. Effective training can, "prevent workplace injuries and illnesses, improve compliance with laws and regulations, reduce costs (including workers' compensation premiums), engage workers, increase productivity, and enhance overall business operations" [16]. This is particularly relevant in high risk environments, such as cattle feedyards. Indeed, according to the Agricultural Safety and 
Health Council of America (ASHCA), for every dollar invested in farm safety, there is an estimated \$4-\$6 return [17].

Immigrant workers represent a vulnerable population as defined by the National Institute of Occupational Safety and Health because they have disparate rates of occupational injury and face numerous barriers to health and safety as a result of physical, social, and structural conditions [18]. Although much research has focused on other areas of livestock production, such as swine and dairy cows [13-15,19-22], there is little understanding of immigrant cattle feedyard workers' access to health and safety training and their preferences to receive such information. It is also unclear if the size of the feedyard operation may affect whether or not workers receive training or the type of training they receive, but typically smaller farm operations have fewer safety activities [23]. Understanding what job-related training immigrant cattle feedyard workers report receiving at the job site, as well as their preferences for health and safety training and information, may help agricultural health and safety professionals appropriately respond to this vulnerable worker population, improve worker training initiatives, and may ultimately lead to decreased injuries and fewer workers' compensation claims.

Since Latino immigrants comprise a large percentage of the cattle feedyard workforce, the present study was designed to examine these workers' perceptions of safety training and practices. The research questions explored in this study included: What types of safety training do workers report receiving from their employer? Are there differences in reporting receipt of training based on feedyard size? How do workers prefer to receive occupational safety training and information? Are there differences in preferences based on the demographic profile of the worker? Therefore, the purpose of this paper is two-fold. First, it will highlight preliminary data regarding personal health and safety training that Latino immigrant cattle feedyard workers report receiving from employers in Nebraska and Kansas. Second, it will describe workers' preferences for receiving occupational health and safety information.

\section{Methods}

Preliminary results are based on an ongoing data collection effort as part of the "Health and Safety among Immigrant Cattle Feedyard Workers in the Central States Region" project. Through this project, interviews are being conducted with immigrant cattle feedyard workers in Nebraska and Kansas, with the objectives of testing an ecological stress-based model of immigrant worker health and safety and developing effective training resources for this underserved worker population. To date, 68 structured interviews have been conducted with Latino immigrant cattle feedyard workers in Nebraska and Kansas. All research activities were reviewed and approved by the Institutional Review Board at the University of Nebraska Medical Center.

\subsection{Participants}

To be eligible to participate, workers had to be currently employed on a cattle feedyard in Nebraska or Kansas, be of the age of majority in the state where the interview was conducted (at least 19 years of age in Nebraska or 18 years of age in Kansas), and identify as an immigrant of Hispanic/Latino descent.

\subsection{Procedures}

The "Health and Safety among Immigrant Cattle Feedyard Workers in the Central States Region" study uses a structured questionnaire to assess physical health, occupational context, prevention opportunities, emotional health and stress, and demographic information. Prior to field deployment, the full questionnaire was pilot-tested with five workers and revised to improve interview flow and question comprehension.

Then, bilingual research team members contacted workers and conducted interviews with them off-site after working hours, in as private a location as possible, between August 2017-March 2018. Interviews took approximately $75 \mathrm{~min}$ and could be completed in either English or Spanish, 
based on the worker's language preference. To date, no interviews have been conducted in English. Workers received a $\$ 25$ gift card for participating in the study.

\subsection{Measures}

The present analysis is derived from questions within the occupational context, prevention opportunities, and demographic sections of the questionnaire.

\subsubsection{Job-Related Training}

Reported receipt of training was assessed with the question, "Have you received any health or safety training from your current employer?" Response options were dichotomous, yes or no. If a worker responded that they had received training, then a series of questions about the type of training and language of training followed. If a worker reported not having received any training, then questions related to type and language of training were skipped. All workers were asked if they had ever participated in any OSHA safety training program. All workers were also asked if they were interested in receiving more information on health and safety related to their job, and then a series of questions followed about how they would like to receive information (e.g., in-person training, videos, written materials, online/internet-based modules, fotonovela [a comic or graphic novel that uses stories to educate readers about a topic], smart phone app, text messages, or other), language preference for receiving such information, and if they had any specific job-related health and safety information requests based on their experience (open-ended question).

\subsubsection{Demographic Covariates}

Worker age was measured continuously, but collapsed into two categories for this analysis: $18-30$ and 31 or over. Although the classification for young adults is usually between the ages of 18-24 years of age, in this analysis, a young adult was considered to be between the ages of 18-30, in order to have sufficient number of participants in each group for analysis. English proficiency was assessed through the question, "How well do you speak English?" Response options included not at all, a little, somewhat, and well, which were dichotomized into English proficient (somewhat and well) and non-English proficient (not at all and a little). Sex was either male or female. Level of education was categorical, and responses were collapsed into the following: elementary (grades 1-8), some high school (grades 9-12 but did not graduate), or high school graduate or higher. The size of the feedyard was determined by the number of cattle reported by the worker to be on the feedyard, and categorized into small (less than 1000 head), medium (between 1000-7999 head), large (8000-32,000 head), and extra-large (over 32,000 head). The number of head used to determine each category (with the exception of extra-large) is similar to groupings that are used by the United States Department of Agriculture [24]. The type of feedyard position held by the worker was based on the standard feedyard departments and response options included pen rider/cowboy, hospital/sick pen, cattle processing, feed mill, feed delivery, yard and equipment maintenance, administration, security, or other. Workers could choose one or more of the jobs listed.

\subsection{Analyses Plan}

All data were analyzed used SPSS Version 23 (IBM Corp., Armonk, NY, USA). First, descriptive data were calculated for all variables of interest, including frequencies, means $(M s)$, and standard deviations ( $S D s)$. Then, chi square tests, including Pearson's chi square and Fisher's exact tests, were used to assess bivariate associations between (1) reported receipt of health and safety training and feedyard size, (2) English proficiency of the worker and language in which training and materials were provided, and (3) training and information preferences and worker characteristics such as age, English proficiency, sex, and level of education. 


\section{Results}

The majority of workers were men $(86.8 \%)$, from Mexico (73.5\%), who had limited English proficiency $(61.7 \%)$. The mean age of participants was 38.7 years old $(S D=10.6)$, and $72.1 \%$ had completed less than a high school education. The demographic characteristics of participants are presented in Table 1.

Table 1. Demographic characteristics of participants.

\begin{tabular}{ccc}
\hline Variables & $\boldsymbol{N}(\%)$ & $M(S D)$ \\
\hline Sex & $59(86.8)$ & \\
Male & $9(13.2)$ & \\
\hline Female & & $38.7(10.6)$ \\
\hline Age (years) & $50(73.5)$ & \\
\hline Country of Origin & $7(10.3)$ & \\
Mexico & $5(7.4)$ & \\
Guatemala & $1(1.5)$ & \\
El Salvador & $3(4.4)$ & \\
Puerto Rico & $2(2.9)$ & \\
Cuba & & \\
Other & $49.2(9.1)$ \\
\hline Length of Time in the U.S. (years) & $11(16.1)$ & \\
\hline Relationship Status & $8(11.8)$ & \\
Coupled or Married & & \\
Separated or Divorced & $22(32.4)$ & \\
Single & $27(39.7)$ & \\
\hline Education & $10(14.7)$ & \\
Elementary (grades 1-8) & $9(13.2)$ & \\
Some High School (grades 9-12) & & \\
High School Graduate & & \\
Some College or Technical & $12(17.6)$ & \\
Training & $30(44.1)$ & \\
\hline English Proficiency & $14(17.6)$ & \\
Not at All & & \\
A Little & & \\
Somewhat & & \\
Well & & \\
\hline Average Weekly Pay (\$US) & & \\
\hline
\end{tabular}

Workers were involved in a variety of feedyard jobs. More than half of participants processed cattle, worked the hospital pen, delivered feed, or rode pens (Figure 1). Although fewer women were employed on feedyards in our sample, they were represented in all job categories. The size of the feedyards where participants worked ranged between 100 and 110,000 head of cattle, $M=26,994$, $S D=23,320$, median $=25,000$, mode $=40,000$.

More than $60 \%$ of workers reported receiving some sort of health or safety training from their current employer. There was not a significant difference in reporting receipt of training based on feedyard size. Among those who reported receiving training, the most frequent types included in-person training, videos, and shadowing or watching another worker. Most training and materials were concordant with the language ability of the worker. For example, if the worker had limited English proficiency, then training was likely to be provided in Spanish, $\chi^{2}(1, N=68)=11.78, p=.001$. However, there were cases of limited English-proficient workers reporting receiving training or materials solely in English. Only about $13 \%$ of workers had ever participated in any formal OSHA safety training program.

Nearly $90 \%$ of workers were interested in receiving more information about health and safety issues related to their job. A majority of participants (83.6\%) preferred to receive information in Spanish. Workers preferred information to be provided through in-person training at the job site, videos (particularly those accessible through media sources such as YouTube), and written materials 
(Figure 2). There were significant differences in worker preferences for receiving information based on English proficiency and level of education. English proficient workers were more likely to prefer receiving information online than non-English proficient workers, $\chi^{2}(1, N=68)=5.22, p=.02$. Workers who had completed a high school education or higher were more likely to prefer receiving information online than those with less formal education, $\chi^{2}(1, N=68)=8.34, p=.02$.

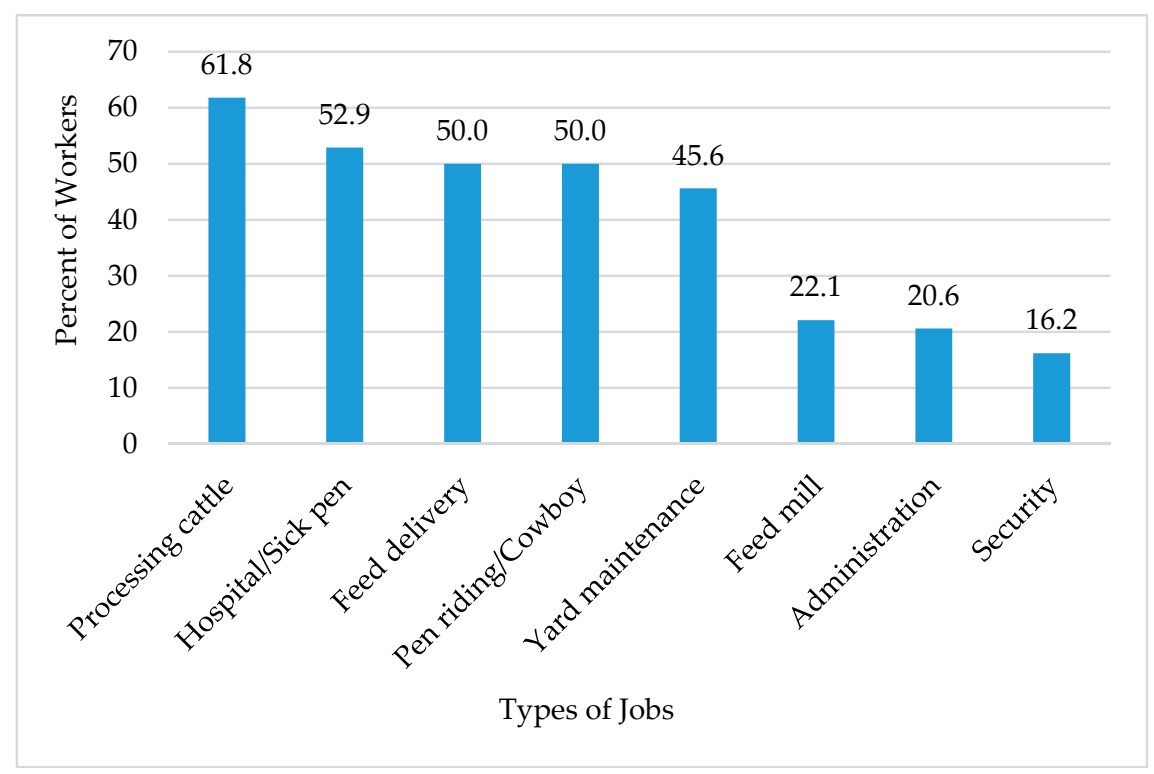

Figure 1. Percent of participants by job type.

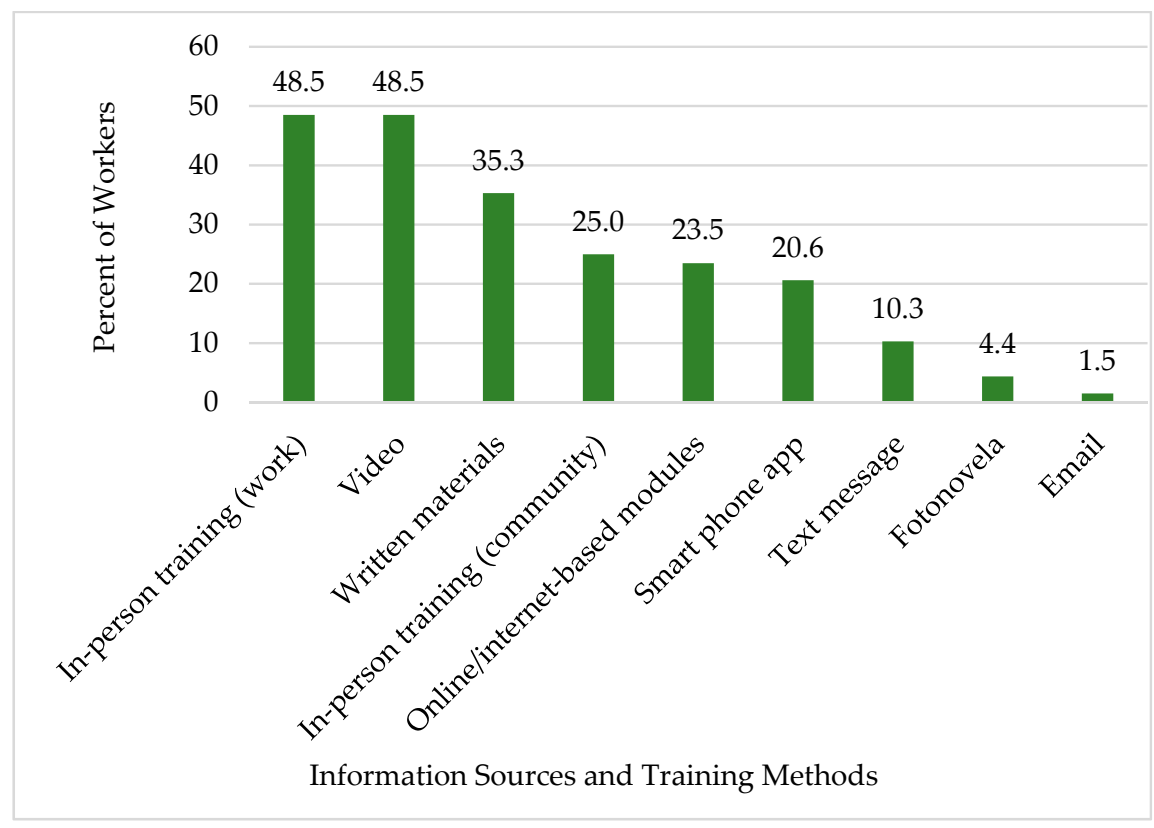

Figure 2. Preferred information sources and training methods.

All workers reported that health and safety at work was important, and some of the reasons they cited for it being important included wanting to be able to work, not getting injured, and being able to support their families. Specific topics that workers were interested in obtaining more information about are listed in Table 2 below. 
Table 2. Specific training topics of interest identified by workers.

\begin{tabular}{|c|c|}
\hline Managing Risks on the Feedyard & Personal Interests \\
\hline $\begin{array}{l}\text { - Hazard and injury reporting } \\
\text { - } \quad \text { Cattle moving techniques } \\
\text { - } \quad \text { Pest management } \\
\text { - Teamwork }\end{array}$ & $\begin{array}{l}\text { - } \text { Chemical and equipment safety } \\
\text { - Injury prevention techniques } \\
\text { - Low-stress cattle handling } \\
\text { - Respiratory health } \\
\text { - Workers' compensation } \\
\text { - Zoonoses }\end{array}$ \\
\hline
\end{tabular}

\section{Discussion}

These preliminary data describe job-related training, language of training and materials, and worker preferences for health and safety information and practices as reported by a small sample of Latino immigrant cattle feedyard workers in Nebraska and Kansas.

The findings showed that the majority of participants processed cattle, worked the hospital pen, delivered feed, or rode pens. Based on data provided from the AgriServices Agency (a provider of insurance to agricultural operations), these jobs (e.g., cowboys, pen riders, and truck drivers) had a higher number of injuries than other feedyard jobs [25]. Previous research has demonstrated that immigrant workers may be concentrated in riskier types of jobs where there is a higher potential for injury or illness [26,27]. In fact, across industries, about one-fifth of all occupational fatalities in the United States occurred to foreign-born workers [4].

Although a majority of workers reported receiving training, almost $40 \%$ reported that they had not received training. This contrasts a 2010 Nebraska Extension survey that indicated that $72 \%$ of feedyard workers had received safety training [28]. Regardless, it is clear there is room for improvement. Safety and health training should be required for all workers given the hazardous nature of agricultural jobs [29]. Training should be required not just for newly hired employees, but also for those with more experience [22,30]. At a minimum, employees should be trained on key OSHA standards including the General Duty Clause, those specifically related to agriculture, and applicable general industry standards [11,31,32]. Workers may also be encouraged to complete a specific 10- or 30-h OSHA training program if their job tasks so warrant, which may increase their knowledge and confidence in safety and, over time, help the feedyard to maintain compliance with various OSHA regulations.

Training should not just be solely for regulatory compliance, but instead, it is also an opportunity to develop feedyard staff. Agricultural employers may consider asking their workers what training topics are of interest and tailoring training opportunities to workforce needs. In this study, participants identified several topics for training that were of interest, including animal handling, injury prevention techniques, workers' compensation, and hazard and injury reporting. Although many of these topics are similar to what has been found with immigrant dairy workers [22], other topics, such as teamwork, were also mentioned. It is important that employers conduct regular appraisals of workforce training needs.

Results also highlighted that there were workers who received training in English who were not proficient in English. Although this may meet a requirement for providing training to employees, workers may not obtain or understand the necessary health and safety information being provided to them. Occupational health and safety training materials and methods should be culturally, linguistically, and logistically appropriate for workers. For example, training should be provided in the workers' primary language if possible, particularly if it is a common language, such as Spanish. Moreover, because of the relatively low level of formal education completion, materials should be developed at a low reading level, and include pictures and symbols, instead of using text heavy formats, like books or manuals $[19,33]$. Trainers may consider using stories, games, role playing scenarios, verbal quizzes, peer-to-peer learning, or other types of popular education techniques, and supplementing with less engaging training methods, such as written materials, as reinforcement $[14,19,34]$. 
The present findings demonstrated that workers were interested in receiving more occupational health and safety information and would like it to be provided through in-person training at the job site and through videos. Results showed differences in preferring online materials based on English proficiency and the level of formal education completion of the worker. Agricultural employers may need to be prepared to provide additional support for workers who are non-English proficient or have lower levels of formal education if online training methods are used. Understanding workers' preferences for information and training can help to tailor the methods that are used and increase the relevance of the information for workers.

Since regular training can positively affect worker behaviors on the job [35], it is vital and should be incorporated into an overall safety program to prevent and reduce occupational injuries and illnesses on cattle feedyards. Agricultural employers will need to assess their capacity to provide training as they develop their safety program. They may need to seek support from agricultural safety agents, insurance consultants, or find training and information resources from other sources. Agricultural employers have an opportunity to improve the health and wellbeing of their employees by setting clear expectations for behavior, showing employees that they are concerned about their safety, and actively protecting workers, such as by providing appropriate training [36]. Future research should explore the influence of workplace safety climate within the cattle feedyard industry.

Inadequate safety and health training procedures can result in occupational injuries, stress, and physical and mental health problems [37] that could cascade into difficulties for workers' interactions with their colleagues, as well as with family members. Work-related safety problems can affect productivity and the economic wellbeing of the feedyard and communities. Furthermore, such added challenges could exacerbate the existing burdens of many individuals and families living in poverty or facing discrimination from living in relatively isolated rural communities. Research is needed to directly explore the possible damaging cascading consequences to workers, as well as to their families [38].

Several limitations of this study should be noted. First, research with immigrant workers is difficult, particularly if the participants feel at risk; therefore, these findings are subject to the amount and depth of information a participant was willing to share with the interviewer. Furthermore, a social desirability bias, the tendency to respond in a way that may be viewed favorably by the interviewer, may have affected the results. We speculate that fear of repercussions from reporting inadequate training or safety procedures could increase false reports of such practices, suggesting that training may in fact be over-reported. Reports of training have not been corroborated with employer records. Given the need for workers to be free to report on their experiences, the tradeoffs in methodology were difficult to overcome. Future studies should obtain observational and objective measures of worker training, such as employer records, as well as explore the relations among safety training, worker injuries, and compensation claims. Second, this study uses cross-sectional data and represents only a snapshot in time. Longitudinal studies are needed to examine the long-term consequences of work-related safety issues. Our study population only includes Latino immigrant workers on cattle feedyards; therefore, the results may not be representative of other worker populations or other areas of livestock production. Future research that examines these issues in larger and more representative populations is needed. Finally, because of the limited sample size, we are unable to describe, with certainty, differences between small and large operations, but such differences may exist.

Despite these limitations, the present study yields rare information on work-related safety training and practices among Latino immigrant cattle feedyard workers. The present study had a number of additional strengths, including conducting the research outside of the work environment to reduce fear or anxiety related to sharing sensitive information about the worker's employment situation, as well as the use of native Spanish-speaking interviewers. Moreover, the evidence yielded important information that can be used to begin to develop and test comprehensive and effective safety training programs. 


\section{Conclusions}

All workers should receive job-related health and safety training, and immigrant cattle feedyard workers are interested in such training. Integrating workers' preferences and employer capacity may help to tailor feasible solutions. Indeed, there is an opportunity to develop and deploy culturally, linguistically, logistically, and literacy-appropriate health and safety training for this population. The present findings can guide the development of future materials, outreach, and training strategies to better suit the needs of the growing and necessary immigrant workforce in production agriculture, which could lead employers and insurers to receiving a stronger return on their investment in cattle feedyard workers and their families.

Author Contributions: Conceptualization, A.K.R., G.C., and K.M.G.; Data curation, A.K.R.; Formal analysis, A.K.R.; Funding acquisition, A.K.R., G.C., and K.M.G.; Investigation, A.K.R., C.B., A.F., and R.G.; Methodology, A.K.R., G.C., and K.M.G.; Project administration, A.K.R.; Supervision, A.K.R., G.C., and K.M.G.; Writing-Original draft, A.K.R.; Writing-Review \& editing, A.K.R., G.C., K.M.G., C.B., A.F., and R.G.

Funding: This research was funded by the National Institute for Occupational Safety and Health (NIOSH) grant number U54 OH010162 through the Central States Center for Agricultural Safety \& Health.

Acknowledgments: We would like to thank all of the cattle feedyard workers who participated in this study as well as acknowledge the contributions of research team members Marcela Carvajal-Suarez and Meredith McGinley.

Conflicts of Interest: The authors declare no conflict of interest. The funders had no role in the design of the study; in the collection, analyses, or interpretation of data; in the writing of the manuscript, and in the decision to publish the results.

\section{References}

1. Grant, K.; University of Nebraska Medical Center, Omaha, NE, USA. Personal communication, 2015.

2. Douphrate, D.I.; Stallones, L.; Lumber Kolstrup, C.; Nonnenmann, M.W.; Pinzke, S.; Hagevoort, G.R. Work-related injuries and fatalities on dairy farm operations-A global perspective. J. Agromed. 2013, 18, 256-264. [CrossRef] [PubMed]

3. Ramos, A.K.; Fuentes, A.; Carvajal-Suarez, M. Self-reported occupational injuries and perceived occupational health problems among Latino immigrant swine confinement workers in Missouri. J. Environ. Public Health 2018. [CrossRef] [PubMed]

4. U.S. Bureau of Labor Statistics. Incidence Rates of Non-Fatal Occupational Injuries and Illnesses by Industry and Case Types; U.S. Bureau of Labor Statistics: Washington, DC, USA, 2015. Available online: https:/ / www.bls.gov/iif/ oshwc/osh/os/ostb4732.pdf (accessed on 20 July 2018).

5. U.S. Bureau of Labor Statistics. Fatal Occupational Injuries in 2016; U.S. Bureau of Labor Statistics: Washington, DC, USA, 2016. Available online: https:/ / www.bls.gov/iif/oshwc/cfoi/cfch0015.pdf (accessed on 25 July 2018).

6. Kansas Department of Labor. Fatal Occupational Injuries by Industry and Event or Exposure, Kansas; Kansas Department of Labor: Topeka, KS, USA, 2015. Available online: https:/ /klic.dol.ks.gov/admin/gsipub/ htmlarea/uploads/2015CFOITableA1.pdf (accessed on 25 July 2018).

7. U.S. Bureau of Labor Statistics. Fatal Work Injuries in Nebraska-2016; U.S. Bureau of Labor Statistics: Washington, DC, USA, 2016. Available online: https://www.bls.gov/regions/midwest/news-release/ fatalworkinjuries_nebraska.htm (accessed on 26 July 2018).

8. Birch, J.; Brooks, K. 2015 Nebraska Feedyard Labor Cost Benchmarks and Historical Trends; University of Nebraska-Lincoln Extension: Lincoln, NE, USA, 2015. Available online: http:/ / extensionpublications. unl.edu/assets/pdf/ec836.pdf (accessed on 26 July 2018).

9. Wagner, J.J.; Archibeque, S.L.; Feuz, D.M. The modern feedlot for finishing cattle. Annu. Rev. Anim. Biosci. 2014, 2, 535-554. [CrossRef] [PubMed]

10. Occupational Safety and Health Administration. OSHA's Recordkeeping Rule; Occupational Safety and Health Administration: Washington, DC, USA, 2015. Available online: https:/ /www.osha.gov/recordkeeping2014/ records.html (accessed on 18 August 2018).

11. Smith Thomas, H. Keeping on top of OSHA regulations. Progres. Cattlem. 2016. Available online: https:// www.progressivecattle.com/topics/facilities-equipment/keeping-on-top-of-osha-regulations (accessed on 24 August 2018). 
12. Ramos, A.K. A human rights-based approach to farmworker health: An overarching framework to address the social determinants of health. J. Agromed. 2018, 23, 25-31. [CrossRef] [PubMed]

13. Ramos, A.K.; Fuentes, A.; Trinidad, N. Perception of occupational risks, personal protective equipment (PPE) use, and prevention opportunities among Latino immigrant hog CAFO workers in Missouri. Safety 2016, 2, 25. [CrossRef] [PubMed]

14. Román-Muñiz, I.N.; Van Metre, D.C.; Garry, F.B.; Reynolds, S.J.; Wailes, W.R.; Keefe, T.J. Training methods and association with worker injury on Colorado dairies: A survey. J. Agromed. 2006, 11, 19-26. [CrossRef] [PubMed]

15. Rovai, M.; Carroll, H.; Foos, R.; Erickson, T.; Garcia, A. Dairy tool box talks: A comprehensive worker training in dairy farming. Public Health Front. 2016, 4, 136. [CrossRef] [PubMed]

16. Occupational Safety and Health Administration. Recommended Practices for Safety and Health Programs; Occupational Safety and Health Administration: Washington, DC, USA, 2016. Available online: https: / / www.osha.gov/shpguidelines / (accessed on 8 June 2018).

17. ASHCA. Facts 2015: Be Profitable, Be Safe; ASHCA: Leesburg, VA, USA, 2015. Available online: http:/ / ashca. org/wp-content/uploads/2016/04/ASHCA-2015-Ag-Safety-Fact-Sheet-5.pdf (accessed on 10 June 2018).

18. National Institute of Occupational Safety and Health. Agriculture, Forestry, and Fishing; National Institute of Occupational Safety and Health: Washington, DC, USA, 2018. Available online: https://www.cdc.gov / niosh/programs/agff/bni.html (accessed on 17 August 2018).

19. Menger, L.M.; Rosecrance, J.; Stallones, L.; Román-Muñiz, I.N. A guide to the design of occupational safety and health training for immigrant, Latino/a dairy workers. Public Health Front. 2016, 4, 282. [CrossRef] [PubMed]

20. Sorge, U.S.; Cherry, C.; Bender, J.B. Perception of the importance of human-animal interactions on cattle flow and worker safety on Minnesota dairy farms. J. Dairy Sci. 2014, 97, 4632-4638. [CrossRef] [PubMed]

21. Mullins, C.R.; Pairis-Garcia, M.D.; Campler, M.R.; Anthony, R.; Johnson, A.K.; Coleman, G.J.; Rault, J.L. The development of an interactive computer-based training program for timely and humane on-farm pig euthanasia. J. Vet. Med. Educ. 2018, 45, 405-412. [CrossRef] [PubMed]

22. Liebman, A.K.; Juarez-Carillo, P.M.; Cruz Reyes, I.A.; Keifer, M.C. Immigrant dairy workers' perceptions of health and safety on the farm in America's heartland. Am. J. Ind. Med. 2016, 59, 227-235. [CrossRef] [PubMed]

23. Sinclair, R.C.; Cunningham, T.R. Safety activities in small businesses. Saf. Sci. 2014, 64, 32-38. [CrossRef] [PubMed]

24. U.S. Department of Agriculture, Animal and Plant Health Inspection Service. Feedlot 2011, Part I: Management Practices on U.S. Feedlots with a Capacity of 1000 or More Head; United States Department of Agriculture: Fort Collins, CO, USA, 2013. Available online: https:/ / www.aphis.usda.gov/animal_health/nahms/feedlot/ downloads/feedlot2011/Feed11_dr_PartI.pdf (accessed on 17 August 2018).

25. Duysen, E.; Rautiainen, R.; Kent, D.; Keenen, M.; Bendixsen, C.; Ramos, A.K.; Yoder, A. Improving Feedyard Worker Training to Reduce Injuries and Fatalities-Phase 1 of a Research and Insurance Industry Collaborative Project; Poster presentation at the International Society for Agricultural Safety and Health (ISASH): Halifax, NS, Canada, 2018.

26. Orrenius, P.M.; Zavodny, M. Do immigrants work in riskier jobs? Demography 2009, 46, 535-551. [CrossRef] [PubMed]

27. Schenker, M.B. A global perspective of migration and occupational health. Am. J. Ind. Med. 2010, 53, 329-337. [CrossRef] [PubMed]

28. Jensen, R.; Mark, D.R. 2010 Nebraska Feedyard Labor Cost Benchmarks and Historical Trends; University of Nebraska-Lincoln Extension: Lincoln, NE, USA, 2010. Available online: https:/ /agecon.unl.edu/a9d868a8c610-4d9a-85d7-5a8e3bd6f5bb.pdf (accessed on 24 July 2018).

29. Arcury, T.A.; O’Hara, H.; Grzywacz, J.G.; Isom, S.; Chen, H.; Quandt, S.A. Work safety climate, musculoskeletal discomfort, working while injured, and depression among migrant farmworkers in North Carolina. Am. J. Public Health 2012, 102, S272-S278. [CrossRef] [PubMed]

30. Miller Clouser, J.; Bush, A.; Gan, W.; Swanberg, J. Associations of work stress, supervisor unfairness, and supervisor inability to speak Spanish with occupational injury among Latino farmworkers. J. Immigr. Minor. Health 2018, 20, 894-901. [CrossRef] [PubMed] 
31. Occupational Safety and Health Administration. Agricultural Operations: Standards; Occupational Safety and Health Administration: Washington, DC, USA, 2017. Available online: https://www.osha.gov/dsg/topics/agriculturaloperations/standards.html (accessed on 20 May 2018).

32. Tyler, D. Feedyard accidents and the risks to your bottom line. Feedlot Mag. 2015. Available online: http://feedlotmagazine.com/feedyard-accidents-and-the-risks-to-your-bottom-line/ (accessed on 18 May 2018).

33. De Jesus-Rivas, M.; Acree Conlon, H.; Burns, C. The impact of language and culture diversity in occupational safety. Workplace Health Saf. 2016, 64, 24-27. [CrossRef] [PubMed]

34. Caffaro, F.; Micheletti Cremasco, M.; Bagagiolo, G.; Vigoroso, L.; Cavallo, E. Effectiveness of occupational safety and health training for migrant farmworkers: A scoping review. Public Health 2018, 160, 10-17. [CrossRef] [PubMed]

35. Toppazzini, M.A.; Konrad Wiener, K.K. Making workplaces safer: The influence of organisational climate and individual differences on safety behavior. Heliyon 2017, 3, e00334. [CrossRef] [PubMed]

36. Gillen, M.; Baltz, D.; Gassel, M.; Kirsch, L.; Vaccaro, D. Perceived safety climate, job demands, and coworker support among union and nonunion injured construction workers. J. Saf. Res. 2002, 33, 33-51. [CrossRef]

37. Ramos, A.K. Precarious Work, Invisible People, Unjust Livelihoods: A Social Ecological Model of Migrant Farmworker Health in the Midwest. Ph.D. Thesis, Clemson University, Clemson, SC, USA, 2017.

38. Carlo, G.; McGinley, M.; Ramos, A.K.; Gamboa, R.; Fuentes, A.; Grant, K. Workplace Climate, Protective Factors, and Mental Health in Latino Immigrant Cattle Feedlot Workers; Poster Presentation at the Cambio de Colores Annual Conference: Kansas City, MO, USA, 2018.

(C) 2018 by the authors. Licensee MDPI, Basel, Switzerland. This article is an open access article distributed under the terms and conditions of the Creative Commons Attribution (CC BY) license (http:/ / creativecommons.org/licenses/by/4.0/). 